\title{
Sleeping problems during pregnancy-a risk factor for postnatal depressiveness
}

\section{Pietikäinen, Johanna T.}

2019-06

Pietikäinen , J T , Polo-Kantola , P , Pölkki , P , Saarenpää-Heikkilä , O , Paunio , T \& Paavonen, E J 2019 , ' Sleeping problems during pregnancy-a risk factor for postnatal depressiveness ' , Archives of Women's Mental Health , vol. 22 , no. 3 , pp. 327-337 . https://doi.org/10.1007/s00737

http://hdl.handle.net/10138/303937

https://doi.org/10.1007/s00737-018-0903-5

publishedVersion

Downloaded from Helda, University of Helsinki institutional repository.

This is an electronic reprint of the original article.

This reprint may differ from the original in pagination and typographic detail.

Please cite the original version. 


\title{
Sleeping problems during pregnancy-a risk factor for postnatal depressiveness
}

\author{
Johanna T. Pietikäinen ${ }^{1,2}$ (D) Päivi Polo-Kantola ${ }^{3} \cdot$ Pirjo Pölkki $^{4} \cdot$ Outi Saarenpää-Heikkilä ${ }^{5,6} \cdot$ Tiina Paunio ${ }^{1,2}$. \\ E. Juulia Paavonen ${ }^{1,7}$
}

Received: 22 March 2018 / Accepted: 9 August 2018 / Published online: 18 August 2018

(C) Springer-Verlag GmbH Austria, part of Springer Nature 2018

\begin{abstract}
In the general population, sleeping problems can precede an episode of depression. We hypothesized that sleeping problems during pregnancy, including insomnia symptoms, shortened sleep, and daytime tiredness, are related to maternal postnatal depressiveness. We conducted a prospective study evaluating sleep and depressive symptoms, both prenatally (around gestational week 32) and postnatally (around 3 months after delivery) in the longitudinal CHILDSLEEP birth cohort in Finland. Prenatally, 1667 women returned the questionnaire, of which 1398 women participated also at the postnatal follow-up. Sleep was measured with the Basic Nordic Sleep Questionnaire (BNSQ) and depressive symptoms with a 10-item version of the Center for Epidemiological Studies Depression Scale (CES-D). Altogether, $10.3 \%$ of the women had postnatal depressiveness (CES-D $\geq 10$ points). After adjusting for main background characteristics and prenatal depressiveness (CES-D $\geq 10$ ), poor general sleep quality (AOR 1.87, 95\% CI 1.21-2.88), tiredness during the day (AOR 2.19, 95\% CI 1.41-3.38), short sleep $\leq 6$ and $\leq 7 \mathrm{~h}$, sleep latency $>$ $20 \mathrm{~min}$, and sleep loss $\geq 2 \mathrm{~h}$ were associated with postnatal depressiveness (all $p<.050$ ). Postnatally, after the adjustment for background characteristics, virtually all sleeping problems (i.e., difficulty falling asleep (AOR 7.93, 95\% CI 4.76-13.20)), except frequent night awakenings per week or severe sleepiness during the day, were related to concurrent postnatal depressiveness. Thus, several prenatal and postnatal sleeping problems are associated with increased depressive symptoms 3 months postnatally. Screening of maternal prenatal sleeping problems, even without depressive symptoms during pregnancy or lifetime, would help to identify women at an increased risk for postnatal depressiveness.
\end{abstract}

Keywords Sleeping problems $\cdot$ Pregnancy $\cdot$ Postnatal depressiveness $\cdot$ Insomnia $\cdot$ Postpartum depression $\cdot$ Sleep disturbance

Johanna T. Pietikäinen

johanna.t.pietikainen@helsinki.fi

Päivi Polo-Kantola

paivi.polo@utu.fi

Pirjo Pölkki

pirjo.polkki@uef.fi

Outi Saarenpää-Heikkilä

outi.saarenpaa-heikkila@uta.fi

Tiina Paunio

tiina.paunio@helsinki.fi

E. Juulia Paavonen

juulia.paavonen@helsinki.fi
1 Department of Health Solutions, National Institute for Health and Welfare, Mannerheimintie 168, P.O. Box 30, 00271 Helsinki, Finland

2 Psychiatry, University of Helsinki and Helsinki University Hospital, Helsinki, Finland

3 Department of Obstetrics and Gynecology, Turku University Hospital and University of Turku, Turku, Finland

4 Department of Social Sciences, University of Eastern Finland, Kuopio, Finland

5 Pediatric Clinics, Tampere University Hospital, Tampere, Finland

6 Tampere Centre for Child Health Research, University of Tampere and Tampere University Hospital, Tampere, Finland

7 Child Psychiatry, University of Helsinki and Helsinki University Hospital, Helsinki, Finland 


\section{Introduction}

Postnatal mood symptoms, especially postpartum depression (PPD), affect both the mother and the baby with potentially long-lasting consequences (Mayberry et al. 2007; Moehler et al. 2006). Over $80 \%$ of women experience some fluctuations in mood, either in the prenatal period or postnatally, while a considerable proportion of them meet the DSM-IV criteria for major depressive disorder (Steiner 1998). Prevalence estimates on PPD differ to some extent; from 10-15\% (MosesKolko and Roth 2004) to 13-19\% (O'Hara and McCabe 2013).

Women's sleep changes significantly during pregnancy and after delivery (Hedman et al. 2002; Santiago et al. 2001; Parry et al. 2006; Pengo et al. 2018). Physical symptoms and discomfort may cause sleep reduction and fragmentation during pregnancy (Kamysheva et al. 2008; Lee 1998), whereas infants' night wakings are related to sleep disruption in mothers after delivery (Mindell et al. 2015). In the study of Dorheim et al. (2014), sleep duration and mean sleep efficiency reduced after delivery, while reported prevalence of insomnia and self-reported insomnia scores decreased. Coo et al. (2014) used both objective and subjective measures of sleep during late pregnancy and postnatal period and reported sleep fragmentation during late pregnancy; within the first 15 days after childbirth, women had a twofold increase in sleep fragmentation, as well as reduction of sleep duration and efficiency.

Sleeping problems can negatively affect the mood (Baglioni et al. 2010). Previous longitudinal studies have shown that insomnia symptoms in adults can precede an episode of depression (Baglioni et al. 2011; Ford and Kamerow 1989; Perlis et al. 1997). In these lines, prenatal sleeping problems may also increase the risk for PPD (Lawson et al. 2015). For example, Skouteris et al. (2008) reported that poor sleep quality in early-stage pregnancy predicted higher levels of depression later in pregnancy. Moreover, Marques et al. (2011) found that perceived insomnia symptoms during late pregnancy were related to postnatal depressive symptomology. Interestingly, when Marques et al. (2011) controlled for negative affect, positive affect, and lifetime depression, insomnia lost its predictive role. However, all these studies were based on relatively small samples. In the study by Dorheim et al. (2014), with a larger sample of pregnant women $(n=2088)$, prenatal insomnia was associated with postnatal depression only in women with a history of depression.

Although, accordingly, poor perinatal sleep seems to have an impact on maternal mood (Lawson et al. 2015), the role of various prenatal sleeping problems in the development of postnatal depressive symptoms remains unclear. The few existing studies are mostly cross-sectional, based on small samples, and do not adequately report or adjust for previous depression (Bei et al. 2010; Park et al. 2013; Tikotzky 2016; Tomfohr et al. 2015). In addition, the findings are partly conflicting; for example, Coo Calcagni et al. (2012) found no relationship between subjective assessments of sleep in pregnancy and PPD symptomatology, and Krawczak et al. (2016) $(n=83)$ found that changes in biological rhythms across the perinatal period, rather than sleep quality, predicted worsening of postnatal depressive symptoms, both in women with or without previous mood disorders.

We conducted a prospective study evaluating the associations between prenatal and postnatal sleeping problems and postnatal depressive symptoms, as well as changes in sleep across late pregnancy to postpartum. We hypothesized that both prenatal and postnatal sleeping problems, such as various insomnia symptoms, short sleep, sleep loss, and daytime tiredness, are associated with postnatal depressive symptoms. The analyses were controlled by relevant confounding factors as well as prenatal depressive symptoms or lifetime depression.

\section{Methods}

This study was a part of a larger population-based, prospectively collected birth cohort CHILD-SLEEP study. The study setting, population, and recruitment procedure are described in detail elsewhere (Paavonen et al. 2017). Women were given the first questionnaire approximately at gestation week (gwk) 32, and the questionnaires were completed and returned approximately at gwk $34 \pm 2.5$ (prenatal time point). Altogether, 1667 women (74.3\% of the informed women) returned the prenatal questionnaires. A small part of the women $(1.2 \%, n=21)$ filled in the questionnaire after delivery, and because the purpose of the study was to assess sleeping problems during pregnancy, their responses were excluded, leaving 1646 prenatal questionnaires to be analyzed.

Three months after delivery, a second set of questionnaires was sent to all women. The mean time for completing the questionnaires after delivery was 98.9 days (SD 14.8 , range $72-215$ days). In the case where the questionnaires were not returned in 2 weeks, a maximum of three reminders were sent every 2 weeks. The first reminder was a text message, the second an e-mail, and the third a phone call. At the postnatal time point, 1421 women (63.3\% of the informed women) returned the questionnaires. Five of these women returned only the postnatal questionnaire, but not the prenatal one, and their responses were excluded. Thus, altogether, 1398 women with responses to the two questionnaires (prenatal and the postnatal) were included in this study. The characteristics of the participating women are described in Table 1. When comparing the sociodemographic data in our sample to that reported by the Finnish Perinatal registry and 
Table 1 Basic characteristics

\begin{tabular}{|c|c|c|c|c|}
\hline Study population & $\begin{array}{l}\text { All } \\
n=1398 \\
\%(n) / \text { mean }(\mathrm{SD})\end{array}$ & $\begin{array}{l}\text { Postnatal CES-D }<10 \text { points } \\
\text { (non-depressive group) } \\
89.7 \%(n=1249) \\
\%(n) / \text { mean }(\mathrm{SD})\end{array}$ & 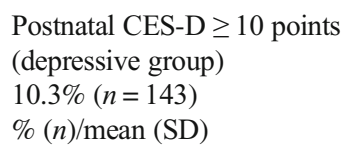 & $p^{\mathrm{a}}$ \\
\hline Age (years) & $30.8(4.5)$ & $30.7(4.5)$ & $30.0(4.5)$ & .069 \\
\hline \multicolumn{5}{|l|}{ Basic education } \\
\hline Comprehensive school & $23.1 \%(321)$ & $22.4 \%(279)$ & $29.4 \%(42)$ & \multirow[t]{2}{*}{.059} \\
\hline High school graduate & $76.9 \%(1070)$ & $77.6 \%(969)$ & $70.6 \%(101)$ & \\
\hline \multicolumn{5}{|l|}{ Vocational education } \\
\hline None or some vocational training & $6.2 \%(84)$ & $5.6 \%(68)$ & $11.3 \%(16)$ & \multirow[t]{3}{*}{.004} \\
\hline Vocational or polytechnic degree & $58.9 \%(802)$ & $58.4 \%(713)$ & $63.1 \%(89)$ & \\
\hline University & $34.9 \%(475)$ & $36.0 \%(439)$ & $25.5 \%(36)$ & \\
\hline \multicolumn{5}{|l|}{ Number of children ${ }^{\mathrm{b}}$} \\
\hline 0 & $49.3 \%(639)$ & $50.1 \%(585)$ & $42.2 \%(54)$ & \multirow[t]{3}{*}{.107} \\
\hline 1 & $33.9 \%(439)$ & $33.0 \%(385)$ & $42.2 \%(54)$ & \\
\hline 2 or more & $16.8 \%(218)$ & $17.0 \%(198)$ & $15.6 \%(20)$ & \\
\hline \multicolumn{5}{|l|}{ Smoking during pregnancy } \\
\hline No & $94.7 \%(1314)$ & $95.3 \%(1185)$ & $90.2 \%(129)$ & \multirow[t]{2}{*}{.018} \\
\hline Yes & $5.3 \%(73)$ & $4.7 \%(59)$ & $9.8 \%(14)$ & \\
\hline Gestational week at delivery & $40.0(1.3)$ & $40.0(1.3)$ & $39.9(1.2)$ & .143 \\
\hline \multicolumn{5}{|l|}{ Monthly income (during pregnancy) } \\
\hline$<1000 €$ & $21.8 \%(297)$ & $20.3 \%(248)$ & $35.3 \%(49)$ & \multirow[t]{3}{*}{$<.001$} \\
\hline $1000-2000 €$ & $52.2 \%(712)$ & $52.9 \%(647)$ & $46.8 \%(65)$ & \\
\hline Over $2000 €$ & $26.0 \%(354)$ & $26.9 \%(329)$ & $18.0 \%(25)$ & \\
\hline \multicolumn{5}{|l|}{ General health } \\
\hline Healthy & $78.3 \%(1082)$ & $79.6 \%(988)$ & $66.7 \%(94)$ & \multirow[t]{2}{*}{$<.001$} \\
\hline At least one disability/illness & $21.7 \%(300)$ & $20.4 \%(253)$ & $33.3 \%(47)$ & \\
\hline \multicolumn{5}{|c|}{ Psychiatric disorders diagnosed by physician (asked at gwk 32) } \\
\hline \multicolumn{5}{|c|}{ Depression } \\
\hline Never & $86.4 \%(1086)$ & $89.4 \%(1002)$ & $61.8 \%(84)$ & \multirow[t]{3}{*}{$<.001$} \\
\hline Earlier & $11.6 \%(146)$ & $9.6 \%(108)$ & $27.9 \%(38)$ & \\
\hline Current (gwk 32) & $2.0 \%(25)$ & $1.0 \%(11)$ & $10.3 \%(14)$ & \\
\hline \multicolumn{5}{|l|}{ Panic disorder } \\
\hline Never & $94.0 \%(1169)$ & $95.1 \%(1061)$ & $85.0 \%(108)$ & \multirow[t]{3}{*}{$<.001$} \\
\hline Earlier & $4.6 \%(57)$ & $3.9 \%(43)$ & $11.0 \%(14)$ & \\
\hline Current (gwk 32) & $1.4 \%(17)$ & $1.1 \%(12)$ & $3.9 \%(5)$ & \\
\hline Schizophrenia, lifetime & $0.3 \%(4)$ & $0.4 \%(4)$ & 0 & .361 \\
\hline ADHD, lifetime & $0.6 \%(8)$ & $0.5 \%(5)$ & $2.4 \%(3)$ & .037 \\
\hline Other mental health problems, lifetime & $2.4 \%(29)$ & $1.7 \%(19)$ & $8.2 \%(10)$ & $<.001$ \\
\hline \multicolumn{5}{|l|}{ Usage of antidepressant drugs } \\
\hline At some point during pregnancy & $2.9 \%(40)$ & $2.5 \%(31)$ & $6.5 \%(9)$ & .008 \\
\hline Postnatally & $2.3 \%(32)$ & $1.3 \%(16)$ & $11.2 \%(16)$ & $<.001$ \\
\hline
\end{tabular}

${ }^{a} p$ for difference between CESD $<>10$ groups was calculated either using the chi-square test (likelihood ratio if number of expected mothers in a cell was less than 5) or $t$ test

${ }^{\mathrm{b}}$ Number of previous children living permanently in the same household

Official Statistics of Finland, the women in our study population were more highly educated (Rusanen et al. 2018) and smoked less than average Finnish pregnant women (Official Statistics of Finland 2018).

\section{Questionnaires}

The prenatal questionnaires included questions of age, education, monthly income, number of children living permanently 
in the same household, smoking, general health, psychiatric diseases, and, as a separate question, past depression diagnosed by a physician (never vs. earlier vs. current (gwk 32)).

Depressiveness: Depressiveness was measured both prenatally and postnatally, using the 10-item version of the Center for Epidemiological Studies Depression Scale, CES-D (Irwin et al. 1999; Radloff 1977), with four response categories for each item. In the case where a woman had answered less than seven items, her response was excluded; otherwise, the missing values were replaced by the individual mean. The items were summarized; a higher score indicated higher depressiveness (scale range 0-30 points). A CES-D sum score of 10 points was used throughout the study as a cutoff point for increased depressive symptoms (Grzywacz et al. 2006; Kohout et al. 1993). In post hoc analyses, where postnatal depression and sleeping problems were analyzed, the CES-D sum score was considered as a continuous variable.

Sleep: The Basic Nordic Sleep questionnaire (BNSQ) (Partinen and Gislason 1995) was used to evaluate the existence of sleeping problems, both prenatally and postnatally. BNSQ insomnia variables include questions of difficulties falling asleep, night awakenings per week, average number of night awakenings per night, early morning awakenings, and poor general sleep quality. In our study, the questions were dichotomized to represent clinically significant problems $(\leq$ 1-2 times per week vs. $\geq 3$ times per week; frequency of nocturnal awakenings $\leq 2$ times per night vs. $\geq 3$ times per night; general sleep quality: good, quite good, intermediate [neither good nor poor] vs. quite poor or poor). Sleep latency (minutes), sleep duration (hours, minutes), and sleep need (hours and minutes) were assessed in an open form. Napping was measured by asking how often women took naps prenatally and postnatally scoring from 1 (never or less than once a month) to 5 (daily or almost daily); also, the duration of naps was assessed (open form, hours, minutes). Sleep latency was asked separately for work days and leisure days and was averaged for the analyses. The average sleep latency was dichotomized at $\leq 20$ vs. $>20 \mathrm{~min}$ to indicate normal vs. prolonged time to fall asleep. Sleep duration was dichotomized to $>6$ vs. $\leq 6 \mathrm{~h}$ and $>7$ vs. $\leq 7 \mathrm{~h}$ to represent normal vs. short sleep. Sleep loss was estimated as the difference between sleep need and average sleep duration, and when it exceeded $2 \mathrm{~h}$, it was considered as clinically significant. Because of the relatively low percentage of women who took naps daily or almost daily, we used the reported sleep time without adding the naps into this figure. The BNSQ insomnia sum score was a sum of the dichotomized five items of insomnia (no sleeping problem vs. problem). A cutoff point of 4 was used to indicate severe insomnia symptoms (at least four different kinds of sleeping problems at least three times per week).

The Epworth Sleepiness Scale (ESS) (Johns 1991) was used to measure daytime sleepiness, both prenatally and postnatally. The scale consists of eight questions rated on a 4-point Likert scale (range 0-24 points). The cutoff value of 11 points was used to indicate excessive daytime sleepiness. The level of tiredness, both prenatally and postnatally, was assessed by the question "Do you consider yourself more tired than other people of your age during the daytime?". Responses were dichotomized ("yes, almost always" and "yes, often" vs. "no" and "do not know").

\section{Statistical analyses}

Mean scores and standard deviations (SD) of the measures of interest (CES-D, sleep latency, sleep duration, sleep need, various insomnia symptoms, total BNSQ sum score, ESS sum score) were compared in women with and without postnatal depressiveness. Pairwise comparisons were conducted using the chi-square test for independence (with Yates' continuity correction) or $t$ tests for independent samples, depending on the type of variable. If the expected count was less than 5 , the Likelihood ratio test was used. A $T$ test for related samples, or McNemar's test, was used to evaluate change between the two time points. Cohen's $d$ (continuous variables) or Cramer's $V$ (dichotomized variables) were used as a measure of effect size. Finally, multivariate logistic regression models were constructed to study whether various sleeping problems, prenatally or postnatally, were associated with increased depressive symptoms postnatally when relevant background factors were taken into account. As background characteristics, we included the women's ages (years), educational level (elementary school vs. vocational school vs. university), smoking during pregnancy (no vs. yes), general health (healthy vs. at least one illness or disability), and number of children living in the family during the pregnancy ( 0 vs. 1 vs. $\geq 2$ ). Prenatally, we controlled for depression in different ways. First, models were controlled for depressiveness during pregnancy (prenatal CESD score $\geq 10$ ) and secondly for lifetime depression. Postnatally, sleeping problems were adjusted for background characteristics. The sleeping problems studied in the statistical models comprised the following variables: difficulties falling asleep ( $\geq 3$ times per week), long sleep latency ( $>20 \mathrm{~min}$ ), frequency of night awakenings ( $\geq 3$ times per week), number of awakenings per night $(\geq 3$ ), early morning awakenings ( $\geq 3$ times per week), general sleep quality (quite poor or poor), severe insomnia symptoms (BNSQ sum score $\geq 4$ ), short sleep ( $\leq 6$ and $\leq 7 \mathrm{~h}$ ), sleep loss ( $\geq 2 \mathrm{~h}$ ), daytime sleepiness (ESS sum score $\geq 11$ ), and tiredness during the day (more tired than others) as the main explanatory variables. Each of the explanatory factors was entered into the models separately. All explanatory factors were assessed both prenatally and postnatally (relative to risk for postnatal depressiveness). The main analyses were repeated using $t$ test and linear regression with CES-D scores without the sleep item ("my sleep was 
restless"). The data was analyzed using IBM SPSS Statistics 24. A two-tailed alpha level of 0.05 was used for analyses.

\section{Results}

Sample characteristics are presented for all women, as well as separately for women with and without postnatal depressiveness in Table 1. Women with lower education $\left(\chi^{2}\right.$ $(2, n=1361)=11.25, p=.004)$, a lower monthly income $\left(\chi^{2}\right.$ $(2, n=1363)=17.56, p<.001)$, who smoked during pregnancy $\left(\chi^{2}(1, n=1387)=5.58, p=.018\right)$, or had at least one disability/illness $\left(\chi^{2}(1, n=1382)=12.49, p<.001\right)$ had more postnatal depressiveness. Other sociodemographic factors were not related to postnatal depressiveness.

The mean CES-D score decreased slightly from a prenatal value of 5.0 (SD 3.5) to a postnatal value of 4.6 (SD 3.8) ( $p$ $<.001)$. Elevated depressiveness scores $(\geq 10)$ were found prenatally in $10.4 \%(n=145)$ of the women and postnatally in $10.3 \%(n=143)$ of women. Most of the women $(84.3 \%$, $n=1171$ ) were not depressive at either time point. However, $5.4 \%(n=75)$ of the women were depressive only prenatally, $5.3 \%(n=74)$ only postnatally, and $5.0 \%(n=69)$ at both time points. Thus, the occurrence of depressiveness remained approximately the same although the depressiveness status altered in half of the depressive women.

The changes in sleeping problems are described in Table 2. All insomnia symptoms, sleep duration (from about 8.1 to $7.5 \mathrm{~h}$ ), and sleep need decreased, while short sleep $\leq 6$ and $\leq 7 \mathrm{~h}$, sleep loss, sleep loss $\geq 2 \mathrm{~h}$, number of frequent awakenings per night, and tiredness during the day increased. Prenatally $9.1 \%(n=127)$ and postnatally $3.3 \%(n=45)$ women reported taking naps daily or almost daily. Prenatally, the mean duration of naps was $1.3 \mathrm{~h}$ (range $0.3-4.5 \mathrm{~h}$, SD $0.7 \mathrm{~h}$ ) and postnatally $1.2 \mathrm{~h}$ (range $0.5-2.3 \mathrm{~h}, \mathrm{SD} 0.5 \mathrm{~h}$ ).

All of the studied, prenatally reported sleeping problems, except frequent night awakenings ( $\geq 3$ /week) and severe sleepiness during the day, were related to postnatal depressiveness (Table 3; Fig. 1). After adjusting for the background characteristics (please see "Statistical analyses" section), difficulty falling asleep, sleep latency $>20 \mathrm{~min}$, frequent awakenings per night, early morning awakenings, poor general sleep quality, BNSQ insomnia score $\geq 4$, short sleep $\leq 6$ and $\leq 7 \mathrm{~h}$, sleep loss $\geq 2 \mathrm{~h}$, and tiredness during the day were all associated with postnatal depressiveness (all $p<.05$ ) (Table 3). When the models were adjusted for background characteristics and prenatal depressive symptoms (prenatal CES-D $\geq 10$ ), sleep latency $>20 \mathrm{~min}$, poor general sleep quality, short sleep $\leq 6$ and $\leq 7 \mathrm{~h}$, sleep loss $\geq 2 \mathrm{~h}$, and tiredness during the day were still associated with postnatal depressiveness (Table 3).

Finally, when earlier lifetime depression and background characteristics were adjusted for, all the same prenatal sleeping problems were still associated with postnatal depressiveness (all $p<.05$ ) except frequent awakenings per night $(p=.239)$ and early morning awakenings $(p=.052)$, when compared to models adjusted for background characteristics (Table 3, AOR).

As seen in Fig. 2 and Table 4, postnatal sleeping problems were also related to postnatal depressive symptoms. After adjusting for the background characteristics in logistic regression models, difficulties falling asleep, sleep latency $>20 \mathrm{~min}$, night awakenings $\geq 3$ per night, early morning awakenings, poor general sleep quality, BNSQ insomnia score $\geq 4$, short sleep $\leq 6$ and $\leq 7 \mathrm{~h}$, sleep loss $\geq 2 \mathrm{~h}$, and tiredness during the day (all $p<.001$ ) were related to postnatal depressiveness (Table 4). Night awakenings $\geq 3$ times per week $(p=.078)$ or severe sleepiness (ESS score $\geq 11)(p=.123)$ were not related to postnatal depressiveness. Postnatal difficulty falling asleep had the strongest association with ongoing depressive symptoms (AOR 7.93, 95\% CI 4.76-13.20, $p<.001$ ).

Because the 10-item version of CES-D contains an item about sleep ("my sleep was restless"), we repeated the main analyses with $t$ test and linear regression using CES-D scores without the insomnia item. However, the main results remained the same.

\section{Discussion}

We found that both prenatal and postnatal sleeping problems are crucial for the occurrence of postnatal depressiveness. After adjusting for prenatal depressive symptoms, prenatal long sleep latency, poor general sleep quality, short sleep ( $\leq$ 6 and $\leq 7 \mathrm{~h}$ ), sleep loss $\geq 2 \mathrm{~h}$, and tiredness during the day were related to postnatal depressiveness. Furthermore, virtually all kinds of sleeping problems (except night awakenings $\geq 3$ times per week and severe sleepiness during the day) postnatally were associated with postnatal depressiveness. Of the associative postnatal sleeping problems, difficulty falling asleep showed the strongest association. Thus, screening the existence of sleeping problems may help to identify women at risk for developing or worsening PPD. On the basis of our findings, screening should comprise at least four sleep items: sleep latency $>20 \mathrm{~min}$, poor general sleep quality, short sleep $\leq 7 \mathrm{~h}$, and tiredness during the day.

The main aim of our study was to investigate the relationship between prenatal sleeping problems and postnatal depressiveness. According to our hypothesis, we found a clear association with prenatal sleeping problems and increased depressiveness postpartum even after adjustment for prenatal depressiveness. This is in accordance with previous studies (summarized in Okun 2016) showing constant association of poor sleep with recurrent PPD episodes (for example, Bei et al. 2010; Dorheim et al. 2014; Tomfohr et al. 2015; Wolfson et al. 2003). For example, Goyal et al. (2007) found that selfreported sleeping problems in the third trimester were 


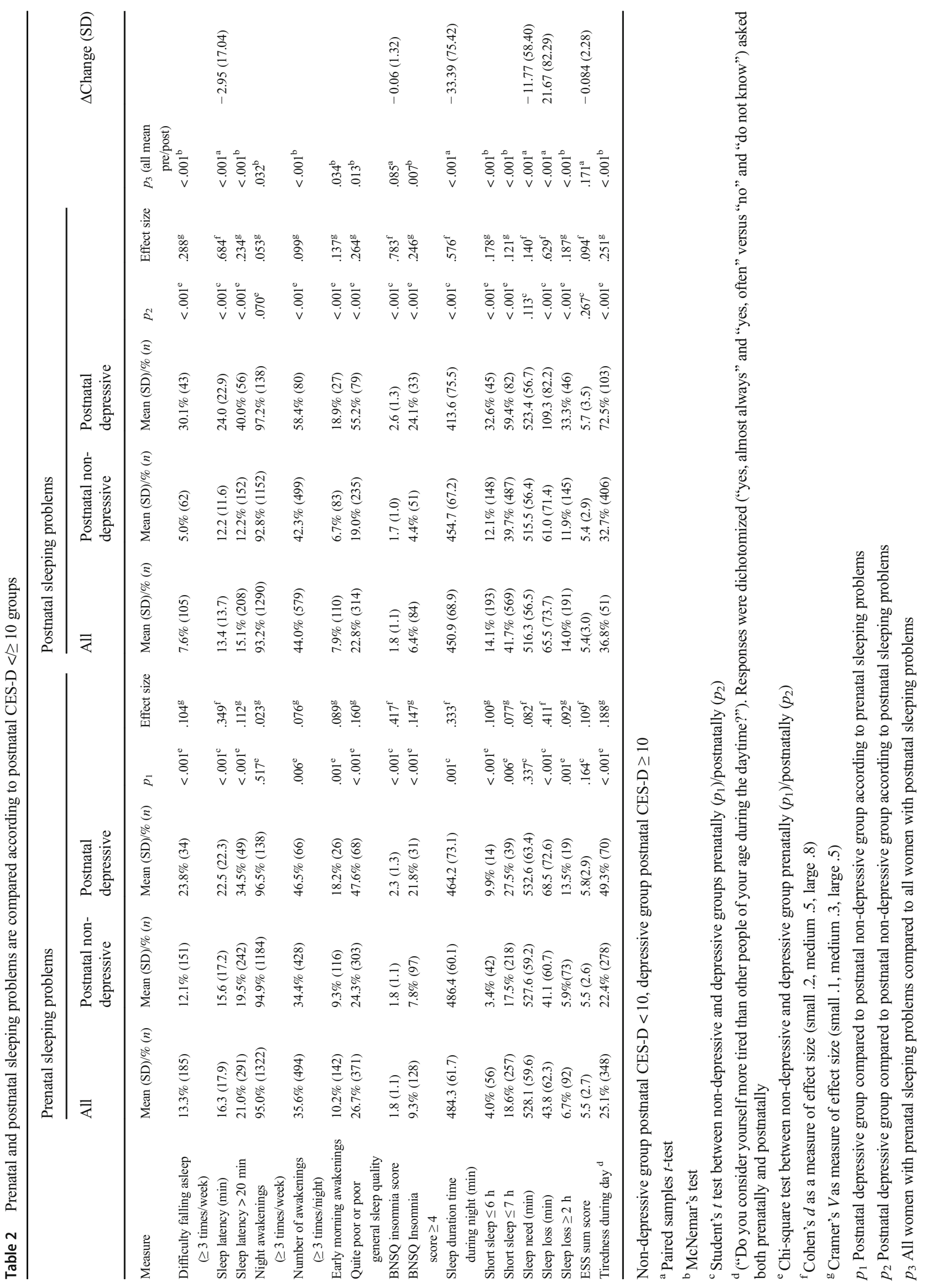




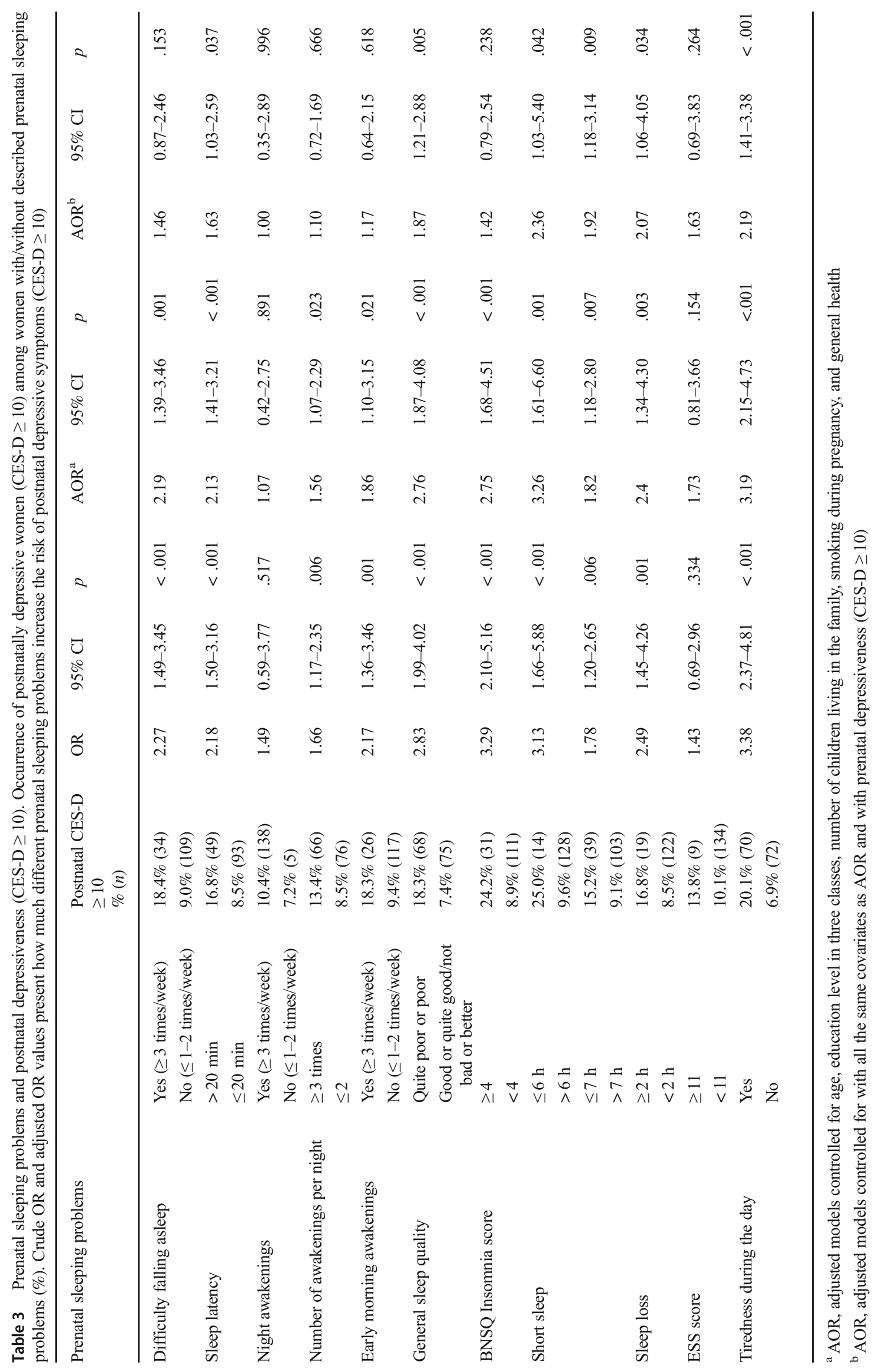


Fig. 1 Prenatal sleeping problems vs. postnatal CES-D mean score with mean standard error bars. Independent $t$ test between yes/no groups, $* * p<.001, * p<.05$

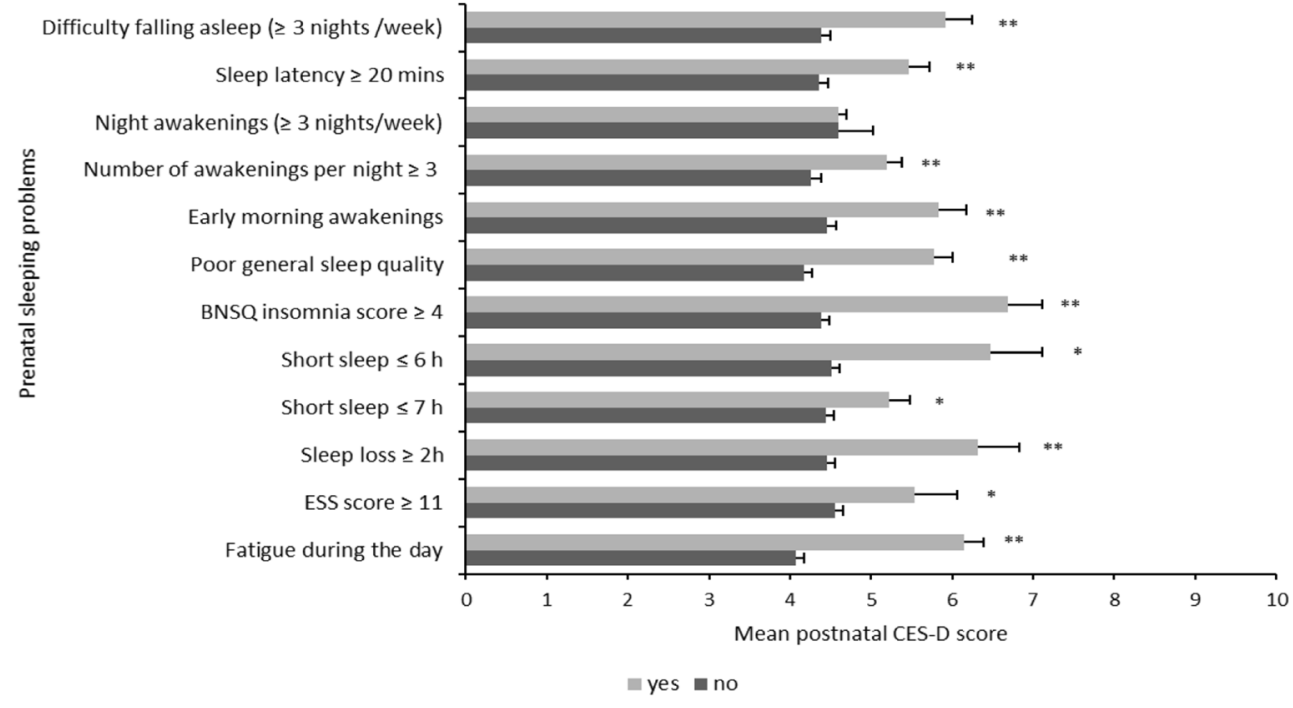

findings, also most of the prenatal sleeping problems remained significant risk factors for postnatal depressiveness after adjustment for earlier lifetime depression. While Dorheim et al. concluded their statement based on the insomnia summary score, it is worth noting that in our study the prenatal insomnia summary score lost its association with postnatal depressiveness after adjustment for prenatal depressiveness. This may indicate that not all aspects of insomnia symptoms induce depressiveness.

In a review by Lawson et al. (2015), 17 out of 20 studies found an association between subjectively reported sleep disruption in postpartum and the development of depressive symptoms in postpartum/PPD diagnosis. Interestingly, Posmontier (2008) reported that among women with PPD, worsening sleep quality in postpartum (measured by actigraphy) predicted the severity of PPD symptoms. In our study, we also evaluated the link between sleep and depressiveness postnatally. We found that sleep onset problems had the strongest association with postnatal
Fig. 2 Postnatal sleeping problems vs. postnatal CES-D mean score with mean standard error bars. Independent $t$ test between yes/no groups, $* * p<.001, * p<.05$

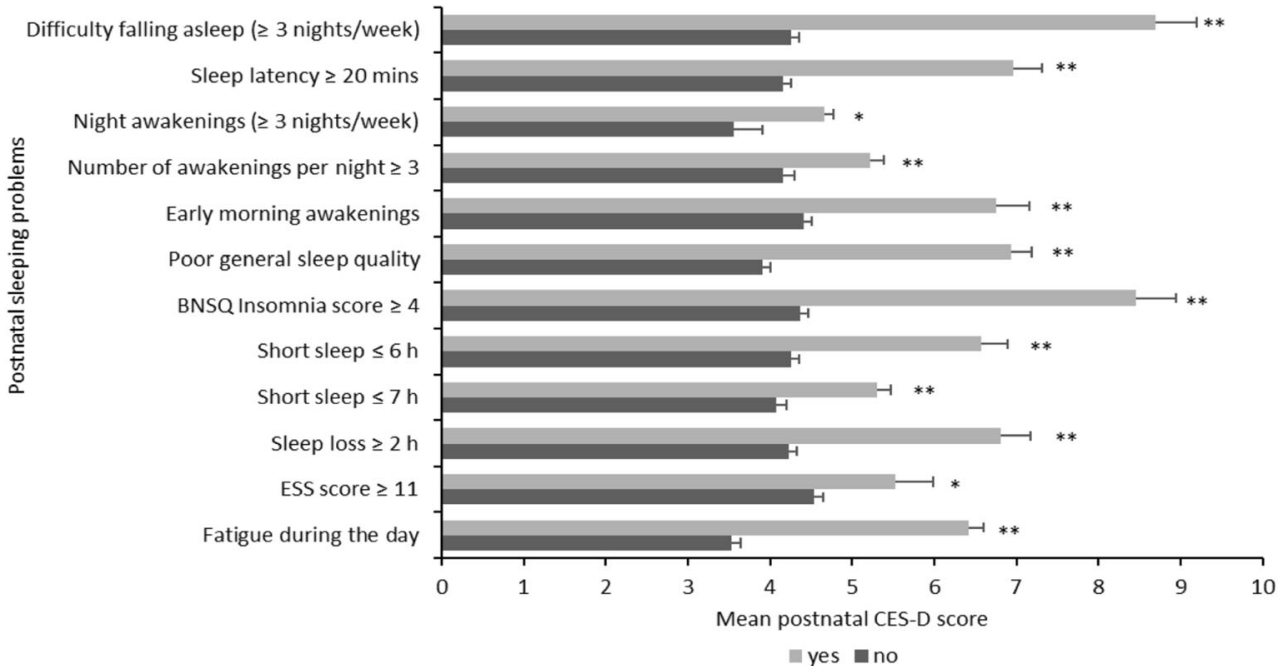

yes $\square$ no 
Table 4 Postnatal sleeping problems and postnatal depressiveness (CESD $\geq 10$ ). Occurrence of postnatally depressive women (CESD $\geq$ 10) among women with/without described postnatal sleeping problems
(\%). Crude OR and adjusted OR values present how much different postnatal sleeping problems increase the risk of postnatal depressive symptoms $(\mathrm{CESD} \geq 10)$

\begin{tabular}{|c|c|c|c|c|c|c|c|c|}
\hline Postnatal sleeping problems & & $\begin{array}{l}\text { Postnatal CES-D } \\
\geq 10 \\
\%(n)\end{array}$ & OR & $95 \% \mathrm{CI}$ & $\mathrm{p}$ & $\mathrm{AOR}^{\mathrm{a}}$ & $95 \% \mathrm{CI}$ & $p$ \\
\hline \multirow[t]{2}{*}{ Difficulty falling asleep } & Yes ( $\geq 3$ times/week) & $41.0 \%(43)$ & \multirow[t]{2}{*}{8.19} & \multirow[t]{2}{*}{$5.28-12.71$} & \multirow[t]{2}{*}{$<.001$} & \multirow[t]{2}{*}{7.93} & \multirow[t]{2}{*}{$4.76-13.20$} & \multirow[t]{2}{*}{$<.001$} \\
\hline & No $(\leq 1-2$ times/week $)$ & $7.8 \%(100)$ & & & & & & \\
\hline \multirow[t]{2}{*}{ Sleep latency } & $>20 \mathrm{~min}$ & $26.9 \%(56)$ & \multirow[t]{2}{*}{4.78} & \multirow[t]{2}{*}{$3.27-6.97$} & \multirow[t]{2}{*}{$<.001$} & \multirow[t]{2}{*}{4.93} & \multirow[t]{2}{*}{$3.20-7.59$} & \multirow[t]{2}{*}{$<.001$} \\
\hline & $\leq 20 \mathrm{~min}$ & $7.2 \%(84)$ & & & & & & \\
\hline \multirow[t]{2}{*}{ Night awakenings } & Yes $(\geq 3$ times/week) & $10.7 \%(138)$ & \multirow[t]{2}{*}{2.70} & \multirow[t]{2}{*}{$0.98-7.45$} & \multirow[t]{2}{*}{.056} & \multirow[t]{2}{*}{2.57} & \multirow[t]{2}{*}{$0.90-7.30$} & \multirow[t]{2}{*}{$<.078$} \\
\hline & No $(\leq 1-2$ times/week $)$ & $4.3 \%(4)$ & & & & & & \\
\hline \multirow[t]{2}{*}{ Number of awakenings per night } & $\geq 3$ times & $13.8 \%(80)$ & \multirow[t]{2}{*}{1.92} & \multirow[t]{2}{*}{$1.34-2.74$} & \multirow[t]{2}{*}{$<.001$} & \multirow[t]{2}{*}{2.09} & \multirow[t]{2}{*}{$1.41-3.09$} & \multirow[t]{2}{*}{$<.001$} \\
\hline & $\leq 2$ & $7.7 \%(57)$ & & & & & & \\
\hline \multirow[t]{2}{*}{ Early morning awakenings } & Yes ( $\geq 3$ times/week) & $24.5 \%(27)$ & \multirow[t]{2}{*}{3.25} & \multirow[t]{2}{*}{$2.02-5.23$} & \multirow[t]{2}{*}{$<.001$} & 3.68 & $2.19-6.20$ & $<.001$ \\
\hline & No $(\leq 1-2$ times/week $)$ & $9.1 \%(116)$ & & & & & & \\
\hline General sleep quality & Quite poor or poor & $25.2 \%(79)$ & 5.26 & $3.68-7.54$ & $<.001$ & 5.28 & $3.56-7.82$ & $<.001$ \\
\hline & $\begin{array}{l}\text { Good or quite good/not } \\
\text { bad or better }\end{array}$ & $6.0 \%(64)$ & & & & & & \\
\hline BNSQ insomnia score & $\geq 4$ & $39.3 \%(33)$ & 6.94 & $4.29-11.23$ & $<.001$ & 6.96 & $4.07-11.93$ & $<.001$ \\
\hline & $<4$ & $8.5 \%(104)$ & & & & & & \\
\hline Short sleep & $\leq 6 \mathrm{~h}$ & $23.3 \%(45)$ & 3.53 & $2.38-5.24$ & $<.001$ & 4.09 & $2.62-6.39$ & $<.001$ \\
\hline & $>6 \mathrm{~h}$ & $7.9 \%(93)$ & & & & & & \\
\hline & $\leq 7 \mathrm{~h}$ & $14.4 \%(82)$ & 2.23 & $1.56-3.18$ & $<.001$ & 2.74 & $1.83-4.10$ & $<.001$ \\
\hline & $>7 \mathrm{~h}$ & $7.0 \%(56)$ & & & & & & \\
\hline Sleep loss & $\geq 2 \mathrm{~h}$ & $24.1 \%(46)$ & 3.71 & $2.50-5.51$ & $<.001$ & 3.71 & $2.39-5.75$ & $<.001$ \\
\hline & $<2 \mathrm{~h}$ & $7.9 \%(92)$ & & & & & & \\
\hline ESS score & $\geq 11$ & $15.1 \%(13)$ & 1.61 & $0.87-2.98$ & .132 & 1.68 & $0.87-3.24$ & .123 \\
\hline & $<11$ & $10.0 \%(130)$ & & & & & & \\
\hline Tiredness during the day & Yes & $20.2 \%(103)$ & 5.45 & $3.70-8.01$ & $<.001$ & 5.49 & $3.59-8.37$ & $<.001$ \\
\hline & No & $4.5 \%(39)$ & & & & & & \\
\hline
\end{tabular}

${ }^{\mathrm{a}} \mathrm{AOR}$, adjusted models controlled for age, education level in three classes, number of children living in the family, smoking during pregnancy, and general health

depressiveness, although practically all studied sleeping problems, except frequent weekly night awakenings and severe daytime sleepiness, were associated with concurrent depressiveness.

\section{Strengths and limitations}

Our study was based on a representative sample of women recruited during pregnancy and followed up after childbirth. In addition, our sample size was large, and the occurrence of postnatal depressiveness fell well within the previously described values (Chaudron et al. 2001; Gotlib et al. 1989; Yonkers et al. 2001). Furthermore, we utilized validated and widely used questionnaires to assess depressiveness, sleep, and sleepiness. The use of the BNSQ enabled us to evaluate sleeping problems in detail, distinguishing general sleep quality, various insomnia subtypes, sleep duration, and sleep loss. However, we did not use standardized interviews to define the diagnosis of depression or the severity of depression, which may lead to the inclusion of versatile populations which do not necessarily suffer from PPD (e.g., adjustment disorders), nor did we use objective measurements of sleep architecture. Nevertheless, in the work of Park et al. (2013) and Bei et al. (2010), subjective perception of sleep was found to be a stronger predictor of PPD symptoms than actigraphy-assessed sleep. Furthermore, we did not have information about the severity of previous depressions. Also, besides the now-investigated questions, there are many other factors which may associate with postnatal depressiveness that were not taken account in this study.

\section{Conclusion}

PPD is a common and persistent disturbance with several potential negative consequences to family life and to child health. Thus, it is clinically highly important to prevent PPD by recognizing the risk factors and individuals at risk as early 
as possible. Based on our findings, women with sleeping problems, both during pregnancy and after delivery, are at an increased risk for postnatal depressiveness. Prenatally, especially poor general sleep quality and excessive daytime tiredness, and postnatally, especially frequent sleep onset problems, but also almost all kind of sleeping problems, indicate the risk. Therefore, it is important that the presence of possible sleeping problems are acknowledged and adequately treated, both prenatally and postnatally. These findings also call for new studies on the prevention of PPD.

Author contribution EJP, TP, and OSH designed the study. JTP, EJP, and PP-K were primarily responsible for data analysis and writing of the article. OSH, TP, and PP contributed critically to the writing of the article.

Funding The project was funded by the Academy of Finland (no. 134880 and 253346 TP; no. 308588 EJP, no. 277557 OSH), Gyllenberg Foundation (TP), Yrjö Jahnsson Foundation, Foundation for Pediatric Research (EJP), Finnish Cultural Foundation (EJP), the Competitive Research Financing of the Expert Responsibility area of Tampere University Hospital (OSH), Arvo ja Lea Ylppö Foundation and Doctors' Association in Tampere (OSH), Finnish Psychiatric Association (JP), Competitive Research Financing of the Expert Responsibility area of Helsinki University Hospital (JP), and Emil Aaltonen Foundation (JP).

\section{Compliance with ethical standards}

All procedures performed in studies involving human participants were in accordance with the ethical standards of the institutional and national research committee and with the 1964 Helsinki declaration and its later amendments or comparable ethical standards. Informed consent was obtained from all individual participants included in the study.

Conflicts of interest All authors declare that they have no conflicts of interest.

\section{References}

Baglioni C, Spiegelhalder K, Lombardo C, Riemann D (2010) Sleep and emotions: a focus on insomnia. Sleep Med Rev 14:227-238. https:// doi.org/10.1016/j.smrv.2009.10.007

Baglioni C, Spiegelhalder K, Nissen C, Riemann D (2011) Clinical implications of the causal relationship between insomnia and depression: how individually tailored treatment of sleeping difficulties could prevent the onset of depression. EPMA J 2:287-293. https:// doi.org/10.1007/s13167-011-0079-9

Bei B, Milgrom J, Ericksen J, Trinder J (2010) Subjective perception of sleep, but not its objective quality, is associated with immediate postpartum mood disturbances in healthy women. Sleep 33:531538

Chaudron LH, Klein MH, Remington P, Palta M, Allen C, Essex MJ (2001) Predictors, prodromes and incidence of postpartum depression. J Psychosom Obstet Gynaecol 22:103-112

Coo Calcagni S, Bei B, Milgrom J, Trinder J (2012) The relationship between sleep and mood in first-time and experienced mothers. Behav Sleep Med 10:167-179. https://doi.org/10.1080/15402002. 2012.668147

Coo S, Milgrom J, Trinder J, (2014) Mood and objective and subjective measures of sleep during late pregnancy and the postpartum period.
Behav Sleep Med 12(4):317-330. https://doi.org/10.1080/ 15402002.2013.801348

Dorheim SK, Bjorvatn B, Eberhard-Gran M (2014) Can insomnia in pregnancy predict postpartum depression? A longitudinal, population-based study. PLoS One 9:e94674. https://doi.org/10. 1371/journal.pone.0094674

Ford DE, Kamerow DB (1989) Epidemiologic study of sleep disturbances and psychiatric disorders. An opportunity for prevention? JAMA 262:1479-1484

Gotlib IH, Whiffen VE, Mount JH, Milne K, Cordy NI (1989) Prevalence rates and demographic characteristics associated with depression in pregnancy and the postpartum. J Consult Clin Psychol 57:269-274

Goyal D, Gay CL, Lee KA (2007) Patterns of sleep disruption and depressive symptoms in new mothers. J Perinat Neonatal Nurs 21: 123-129. https://doi.org/10.1097/01.JPN.0000270629.58746.96

Grzywacz JG, Hovey JD, Seligman LD, Arcury TA, Quandt SA (2006) Evaluating short-form versions of the CES-D for measuring depressive symptoms among immigrants from Mexico. Hisp J Behav Sci 28:404-427

Hedman C, Pohjasvaara T, Tolonen U, Suhonen-Malm AS, Myllylä VV (2002) Effects of pregnancy on mothers' sleep. Sleep Med 3(1):37-42

Irwin M, Artin KH, Oxman MN (1999) Screening for depression in the older adult: criterion validity of the 10-item Center for Epidemiological Studies Depression Scale (CES-D). Arch Intern Med 159:1701-1704

Johns MW (1991) A new method for measuring daytime sleepiness: the Epworth sleepiness scale. Sleep 14:540-545

Kamysheva E, Skouteris H, Wertheim EH, Paxton SJ, Milgrom J (2008) Examination of a multifactorial model of body-related experiences during pregnancy: the relationships among physical symptoms, sleep quality, depression, self-esteem, and negative body attitudes. Body Image 5(2):152-163. https://doi.org/10.1016/j.bodyim.2007. 12.005

Kohout FJ, Berkman LF, Evans DA, Cornoni-Huntley J (1993) Two shorter forms of the CES-D (Center for Epidemiological Studies Depression) depression symptoms index. J Aging Health 5:179 193. https://doi.org/10.1177/089826439300500202

Krawczak EM, Minuzzi L, Hidalgo MP, Frey BN (2016) Do changes in subjective sleep and biological rhythms predict worsening in postpartum depressive symptoms? A prospective study across the perinatal period. Arch Womens Ment Health 19:591-598. https://doi. org/10.1007/s00737-016-0612-x

Lawson A, Murphy KE, Sloan E, Uleryk E, Dalfen A (2015) The relationship between sleep and postpartum mental disorders: a systematic review. J Affect Disord 176:65-77. https://doi.org/10.1016/j. jad.2015.01.017

Lee KA (1998) Alterations in sleep during pregnancy and postpartum: a review of 30 years of research. Sleep Med Rev 2(4):231-242

Marques M, Bos S, Soares MJ, Maia B, Pereira AT, Valente J, Gomes AA, Macedo A, Azevedo MH (2011) Is insomnia in late pregnancy a risk factor for postpartum depression/depressive symptomatology? Psychiatry Res 186:272-280. https://doi.org/10.1016/j.psychres. 2010.06.029

Mayberry LJ, Horowitz JA, Declercq E (2007) Depression symptom prevalence and demographic risk factors among U.S. women during the first 2 years postpartum. J Obstet Gynecol Neonatal Nurs 36: 542-549. https://doi.org/10.1111/j.1552-6909.2007.00191.x

Mindell JA, Sadeh A, Kwon R, Goh DY (2015) Relationship between child and maternal sleep: a developmental and cross-cultural comparison. J Pediatr Psychol 40(7):689-696. https://doi.org/10.1093/ jpepsy/jsv008

Moehler E, Brunner R, Wiebel A, Reck C, Resch F (2006) Maternal depressive symptoms in the postnatal period are associated with long-term impairment of mother-child bonding. Arch Womens Ment Health 9:273-278. https://doi.org/10.1007/s00737-006-0149-5 
Moses-Kolko EL, Roth EK (2004) Antepartum and postpartum depression: healthy mom, healthy baby. J Am Med Womens Assoc (1972) 59:181-191

Official Statistics of Finland (OSF) Perinatal statistics - parturients, deliveries and newborns [e-publication]. Helsinki: National Institute for Health and Welfare (THL) [referred 3.7.2018]. Access method: http://www.stat.fi/til/sysyvasy/index en.html

O'Hara MW, McCabe JE (2013) Postpartum depression: current status and future directions. Annu Rev Clin Psychol 9:379-407. https:// doi.org/10.1146/annurev-clinpsy-050212-185612

Okun ML (2016) Disturbed sleep and postpartum depression. Curr Psychiatry Rep 18:66. https://doi.org/10.1007/s11920-016-0705-2

Paavonen JE, Saarenpaa-Heikkila O, Polkki P, Kylliainen A, PorkkaHeiskanen T, Paunio T (2017) Maternal and paternal sleep during pregnancy in the Child-sleep birth cohort. Sleep Med 29:47-56. https://doi.org/10.1016/j.sleep.2016.09.011

Park EM, Meltzer-Brody S, Stickgold R (2013) Poor sleep maintenance and subjective sleep quality are associated with postpartum maternal depression symptom severity. Arch Womens Ment Health 16:539547. https://doi.org/10.1007/s00737-013-0356-9

Parry BL, Martinez LF, Maurer EL, Lopez AM, Sorenson D, Meliska CJ (2006) Sleep, rhythms and women's mood. Part I. Menstruac cycle, pregnancy and postpartum. Sleep Med Rev 10(2):129-144

Partinen M, Gislason T (1995) Basic Nordic Sleep Questionnaire (BNSQ): a quantitated measure of subjective sleep complaints. J Sleep Res 4:150-155

Pengo MF, Won CH, Bourjeily G (2018) Sleep in women across the life span. Chest 154(1):196-206. https://doi.org/10.1016/j.chest.2018. 04.005

Perlis ML, Giles DE, Buysse DJ, Tu X, Kupfer DJ (1997) Self-reported sleep disturbance as a prodromal symptom in recurrent depression. J Affect Disord 42:209-212

Posmontier B (2008) Sleep quality in women with and without postpartum depression. J Obstet Gynecol Neonatal Nurs 37:722-735; quiz 735-727. https://doi.org/10.1111/j.1552-6909.2008.00298.x
Radloff LS (1977) The CES-D scale: a self report depression scale for research in the general population. Appl Psychol Meas 1: $385-401$

Rusanen E, Lahikainen AR, Pölkki P, Saarenpää-Heikkilä O, Paavonen EJ (2018) The significance of supportive and undermining elements in the maternal representations of an unborn baby. Journal of Reproductive \& Infant Psychology 36:261-275. https://doi.org/10. 1080/02646838.2018.1462476

Santiago JR, Nolledo MS, Kinzler W, Santiago TV (2001) Sleep and sleep disorders in pregnancy. Ann Intern Med 134(5): 396-408

Skouteris H, Germano C, Wertheim EH, Paxton SJ, Milgrom J (2008) Sleep quality and depression during pregnancy: a prospective study. J Sleep Res 17:217-220. https://doi.org/10.1111/j.1365-2869.2008. 00655.x

Steiner M (1998) Perinatal mood disorders: position paper. Psychopharmacol Bull 34:301-306

Tikotzky L (2016) Postpartum maternal sleep, maternal depressive symptoms and self-perceived mother-infant emotional relationship. Behav Sleep Med 14:5-22. https://doi.org/10.1080/15402002. 2014.940111

Tomfohr LM, Buliga E, Letourneau NL, Campbell TS, Giesbrecht GF (2015) Trajectories of sleep quality and associations with mood during the perinatal period. Sleep 38:1237-1245. https://doi.org/ 10.5665/sleep. 4900

Wolfson AR, Crowley SJ, Anwer U, Bassett JL (2003) Changes in sleep patterns and depressive symptoms in first-time mothers: last trimester to 1-year postpartum. Behav Sleep Med 1:54-67. https://doi.org/ 10.1207/S15402010BSM0101_6

Yonkers KA, Ramin SM, Rush AJ, Navarrete CA, Carmody T, March D, Heartwell SF, Leveno KJ (2001) Onset and persistence of postpartum depression in an inner-city maternal health clinic system. Am J Psychiatry 158:1856-1863. https://doi.org/10.1176/appi.ajp.158.11. 1856 